\title{
Comparison of High Intensity Laser and Epicondylitis Bandage in the Treatment of Lateral Epicondylitis
}

\author{
Ali SALLI, ${ }^{1}$ Ekrem AKKURT, ${ }^{2}$ Alparslan Ali İZKİ, ${ }^{2}$ Zafer ŞEN, ${ }^{3}$ Halim YILMAZ ${ }^{2}$ \\ ${ }^{1}$ Department of Physical Medicine and Rehabilitation, Necmettin Erbakan University Meram Medical Faculty, Konya, Turkey \\ ${ }^{2}$ Department of Physical Medicine and Rehabilitation, Konya Training and Research Hospital, Konya, Turkey \\ ${ }^{3}$ Department of Orthopaedics and Traumatology, Konya Training and Research Hospital, Konya, Turkey
}

\begin{abstract}
Objectives: This study aims to investigate the effects of high-intensity laser therapy (HILT) and epicondylitis bandage treatment in patients with lateral epicondylitis (LE).

Patients and methods: Sixty-five patients with unilateral LE (18 males, 47 females; mean age $46.5 \pm 8.1$ years; range 30 to 61 years) with unilateral complaints were included. Patients were randomly assigned into two treatment groups. The first group ( $n=31)$ was treated with HILT for 10 sessions, while the second group $(n=34)$ used only LE bandage for treatment. The patients were assessed for handgrip strength, pain, disability, and quality of life at baseline and sixth week after treatment by using visual analog scale, the Disabilities of the Arm Shoulder and Hand questionnaire, and Short-Form 36 (SF-36).

Results: Both groups showed significant improvement in all evaluated parameters including pain scores, hand grip strength, disability, and SF-36 scores at sixth week after the treatment (all $\mathrm{p}<0.05$ ). A comparison of percentage changes in parameters between treatment groups did not show a significant difference, except for resting visual analog scale $(p=0.036)$ and SF-36 physical component subscale $(p=0.049)$ scores which indicated better improvement in HILT group.

Conclusion: Our findings showed significant improvement in handgrip strength, pain, disability, and quality of life parameters in both groups. However, HILT produced better resting visual analog scale and SF-36 physical component subscale scores compared to LE bandage.

Keywords: Epicondylitis bandage; high intensity laser; lateral epicondylitis.
\end{abstract}

Lateral epicondylitis (LE) is a quite common disease with a prevalence of $1.7 \% .^{1}$ It is mostly seen in the dominant upper extremity of the adults between third and sixth decades of life. ${ }^{2}$ Although its pathogenesis is not clear yet, histopathological examinations demonstrated immature fibroblasts, and disorganized and hypercellular tissue with an ineffective repair process containing non-functional vascular budding. Kraushaar et al. ${ }^{3}$ have therefore suggested the term 'anjio fibroblastic tendinosis', which is used to define repetitive micro trauma caused by excessive use or degenerative changes due to incomplete healing or an injury.
Lifestyle activities are often limited in patients with LE due to decreased hand grip strength and pain caused by tenderness in lateral epicondyle during resisted wrist extension. ${ }^{4}$ Basic targets in the treatment of LE may be summarized as pain relief, acceleration in healing process via reducing arm overuse, all of which subsequently enabling the patient to return to daily life activities. There is a wide spectrum of treatment modalities in LE including drug therapy, non-electrotherapeutical treatments (exercise, manipulation, orthotics, and taping), acupuncture, electrotherapeutical treatment (laser, extracorporeal shock wave therapy, electromagnetic field and ionization, 
ultrasound, and photophoresis), and surgery. ${ }^{5}$ Although orthoses are also known to facilitate daily life activities, reduce pain and increase handgrip strength, their definitive results have not been reported yet. ${ }^{6}$

High-intensity laser therapy (HILT) has been used in the last decade for sports injuries (contusions, tendon injuries, muscle spasms, etc.) and other musculoskeletal disorders. ${ }^{7,8}$ Furthermore, epicondylitis bandage, which applies a compressive force near the origin of the wrist extensor muscles, may be used for such conditions. Thus, in this study, we aimed to investigate the effects of HILT and LE bandage in patients with LE.

\section{PATIENTS AND METHODS}

Sixty-five consecutive unilateral LE patients (18 males, 47 females; mean age $46.5 \pm 8.1$ years; range 30 to 61 years) were included in the study. Patients who had a history of surgery of the upper extremity, local corticosteroid injection and/or physical therapy during the last six months due to LE were excluded. Furthermore, patients with a prior diagnosis of rheumatic diseases, major psychiatric disorder, cervical radiculopathy/ myelopathy, and any upper extremity entrapment neuropathy were excluded. The study protocol was approved by the Necmettin Erbakan University Faculty of Medicine Hospital Ethics Committee. The study was conducted in Konya Training and Research Hospital between February 2014 and March 2015. A written informed consent was obtained from each patient. The study was conducted in accordance with the principles of the Declaration of Helsinki.

Sixty-five elbows with LE were randomized into HILT $(n=31)$ and LE bandage $(n=34)$ groups via coin toss. HILT lasted two weeks, whereas other patients were recommended to wear LE bandage for six weeks. Activity and resting visual analog scale (VAS), Disabilities of the Arm Shoulder and Hand, Short-Form 36 (SF-36), and hand grip strength values were recorded before and after treatment. Post-treatment evaluation was performed at the sixth week following the end of the treatment. Throughout the study, patients were discouraged to use analgesics; yet, they were allowed to use 500-2000 mg paracetamol daily if necessary. Patients were asked not to use analgesics 24 hours prior to the evaluation.

High-intensity laser therapy was applied for 75 seconds at a dose of $4 \mathrm{~W} 6 \mathrm{~J} / \mathrm{cm}^{2}$ (analgesic effect) targeting the most painful areas in circular motion from the center to the outside during the first four sessions. In the subsequent six sessions, therapy was applied for 12 minutes and 30 seconds at a dose of $6 \mathrm{~W} 100-150 \mathrm{~J} / \mathrm{cm}^{2}$ (biostimulation effect) at the pain inflicting region in linear motion. A total of 10 sessions that lasted for two weeks (5 days/week) were performed.

Pain and functional levels of the patients were evaluated by using activity/rest $0-10 \mathrm{~cm}$ VAS and the Disabilities of the Arm Shoulder and Hand questionnaire. The Disabilities of the Arm Shoulder and Hand questionnaire is a 30 -item questionnaire assessing the ability of the patient to perform certain upper extremity activities in the last week. Each item has five possible answers, and is graded on a scale from 1-5. In order to get a total score, at least 27 of the 30 items should be answered. Higher scores indicate higher levels of disability. ${ }^{9}$

Jamar hand dynamometer (Saehan Corporation, Masan, Korea) grip strength measurements, a reliable method, ${ }^{10}$ were used in standing position and with the full extension of the elbow and wrist. Measurements were repeated three times, and average scores were obtained and recorded in kilograms. All measurements were conducted between 10:00 am and 2:00 pm in order to prevent muscle fatigue effects. One-minute intervals were given before each measurement.

Quality of life was evaluated using the SF-36. SF-36 is a 36-item patient-reported survey of patient health, with proven validity and reliability in patients with musculoskeletal disorders. ${ }^{11}$ It consists of eight subsections; physical functioning, social role functioning, physical role functioning, emotional role functioning, mental health, vitality, bodily pain, and general health perceptions. For each section, item scores are coded from 0 (worst health status) to 100 (best health status). Total scores are also obtained for two main domains: a physical component -consisting of physical function, role physical, bodily pain, and general 
Table 1. Demographic data of groups

\begin{tabular}{|c|c|c|c|c|c|}
\hline & \multicolumn{2}{|c|}{ HILT group $(\mathrm{n}=31)$} & \multicolumn{2}{|c|}{ LE bandage group $(\mathrm{n}=34)$} & \multirow[b]{2}{*}{$p$} \\
\hline & $\mathrm{n}$ & Mean \pm SD & $\mathrm{n}$ & Mean \pm SD & \\
\hline Age (years) & & $47.5 \pm 8.9$ & & $45.6 \pm 7.3$ & 0.346 \\
\hline Sex & & & & & 0.435 \\
\hline Male & 8 & & 10 & & \\
\hline Female & 23 & & 24 & & \\
\hline Body mass index $\left(\mathrm{kg} / \mathrm{m}^{2}\right)$ & & $29.4 \pm 3.6$ & & $29.2 \pm 4.7$ & 0.889 \\
\hline Duration of complaints (months) & & $8.7 \pm 12.6$ & & $7.1 \pm 6.8$ & 0.552 \\
\hline Lateral epicondylitis & & & & & 0.770 \\
\hline Dominant & 28 & & 30 & & \\
\hline Non-dominant side & 3 & & 4 & & \\
\hline Employment & & & & & 0.806 \\
\hline Housewife & 20 & & 21 & & \\
\hline Retired & 6 & & 7 & & \\
\hline Employed & 5 & & 6 & & \\
\hline
\end{tabular}

health subscales- and a mental component -consisting of role emotional, social functioning, mental health, and vitality. ${ }^{11}$

\section{Statistical analysis}

IBM SPSS version 20.0 software (IBM Corporation, Armonk, NY, USA) was used for statistical analysis. Descriptive statistical results are shown as mean \pm standard deviation. Baseline characteristics were compared with chi-square and Student's t-tests where appropriate. Before and after treatment results were evaluated through paired sample t-tests. The percentage change of the treatment was compared by using Student's t-test. Statistical significance and confidence intervals were determined as $\mathrm{p}<0.05$ and 95\%, respectively.

\section{RESULTS}

Baseline characteristics of the patients are given in Table 1. Both HILT and LE bandage groups showed significant improvement for all evaluated parameters including pain scores, handgrip strength, disability, and SF-36 scores after sixth week of the treatment (Table 2). Furthermore, comparison of the percentage changes in parameters between treatment groups did not show a significant difference, except for resting VAS ( $p=0.036)$ and SF-36 physical component subscale $(p=0.049)$ scores which indicated better improvement in HILT group. No complication was observed with HILT treatment.

\section{DISCUSSION}

In this study, we showed significant improvements in all parameters including hand grip strength, pain, disability, and quality of life in both groups when comparing the baseline and after treatment values. However, percentage change in VAS score on resting was higher in HILT group compared to LE bandage group.

Table 2. Comparison of clinical variables

\begin{tabular}{|c|c|c|c|c|c|c|}
\hline & \multicolumn{2}{|c|}{ HILT group $(\mathrm{n}=31)$} & \multirow[b]{3}{*}{$p$} & \multicolumn{2}{|c|}{ LE bandage group $(\mathrm{n}=34)$} & \multirow[b]{3}{*}{$p$} \\
\hline & Baseline & After treatment & & Baseline & After treatment & \\
\hline & Mean \pm SD & Mean \pm SD & & Mean \pm SD & Mean \pm SD & \\
\hline VAS-resting & $5.6 \pm 3.3$ & $2.6 \pm 2.4$ & 0.002 & $4.5 \pm 3.4$ & $2.7 \pm 2.9$ & 0.005 \\
\hline VAS-activity & $8.3 \pm 2.0$ & $6.1 \pm 2.4$ & $<0.001$ & $7.6 \pm 2.3$ & $5.3 \pm 3.3$ & 0.002 \\
\hline DASH questionnaire & $51.4 \pm 21.7$ & $37.6 \pm 15.4$ & $<0.001$ & $44.2 \pm 18.0$ & $35.5 \pm 24.2$ & 0.004 \\
\hline SF-36 (physical component) & $36.5 \pm 17.6$ & $66.8 \pm 16.3$ & 0.020 & $35.4 \pm 14.7$ & $53.9 \pm 21.6$ & $<0.001$ \\
\hline SF-36 (mental component) & $46.8 \pm 17.8$ & $62.8 \pm 18.4$ & 0.016 & $41.4 \pm 18.4$ & $56.9 \pm 19.0$ & $<0.001$ \\
\hline Handgrip strength (kg) & $16.1 \pm 9.9$ & $21.9 \pm 13.2$ & $<0.001$ & $20.4 \pm 11.2$ & $24.47 \pm 12.1$ & 0.005 \\
\hline
\end{tabular}


Laser treatment is a noninvasive and painless method that can be easily administered in therapy units for a wide range of conditions. ${ }^{7}$ Low-intensity laser therapy (LILT) is a treatment modality that has been available for the last three decades. There are controversial outcomes regarding the efficacy of LILT in musculoskeletal problems and LE, while some studies suggest that efficacy outcomes are better in LILT when compared to placebo. ${ }^{12,13}$ A meta-analysis has reported that LILT is ineffective for the treatment of LE. ${ }^{5}$

On the other hand, HILT has been used for a wide range of disorders, including low back pain, ${ }^{14,15}$ knee osteoarthritis, ${ }^{16}$ facial paralysis, ${ }^{17}$ and subacromial impingement syndrome. ${ }^{18}$ A study have compared HILT and LILT in the treatment of facial paralysis, and found that HILT was more effective. ${ }^{17}$ Kheshie et al. ${ }^{16}$ have reported HILT and LILT combined with exercise in knee osteoarthritis were effective modalities for decreasing pain and improving the knee function scores after six weeks of treatment. In that study, HILT and exercise therapy was found to be more effective than LILT and exercise therapy, and each of them was better than placebo laser and exercise therapy in patients with knee osteoarthritis. HILT has been reported to reduce inflammation and pain. It uses a particular waveform with regular amplitude peaks, thus, the intervals prevent thermal accumulation phenomena. It is able to rapidly induce photochemical and photothermic effects in the deep tissue. These effects may stimulate collagen production within the tendons and increase blood flow, vascular permeability and cell metabolism; thus, promoting the repair of damaged tendons and removing painful stimuli. ${ }^{19}$ In addition, the analgesic effects of HILT are based on multiple mechanisms of action, including its ability to slow the transmission of the pain stimulus and to increase the production of morphine-mimetic substances. ${ }^{15}$ Although it also has analgesic effects on nerve endings, there is no evidence regarding decreased inflammation. ${ }^{20}$

Epicondylitis bandage applies a compressive force near the origin of the wrist extensor muscles. It has been shown that LE bandage might reduce strength production and enable lengthening of the muscles. ${ }^{21}$
There are few studies comparing the effectiveness of HILT and orthoses. In a prospective, randomized controlled, assessorblinded trial carried out by Dundar et al., ${ }^{8}$ the patients were divided into three groups as HILT, splint, and placebo HILT to investigate the efficacy of splint and HILT. They found that HILT was safe, effective, and easily applicable. A comparison between pre- and posttreatment values revealed significant improvement similar to our study. They also determined that neither of the treatment methods were superior to each other in any of the parameters. However, we found that HILT was more effective in resting VAS and SF-36 physical component subscale scores compared to LE bandage.

The main limitations of our study were the short follow-up period and lack of placebo and combined groups in the evaluation process.

In conclusion, we showed significant improvements in handgrip strength, pain, disability and quality of life parameters in HILT and LE bandage groups. Moreover, HILT was more effective in resting VAS and SF-36 physical component subscale scores compared to LE bandage. Further long-term, randomized controlled trials are needed regarding the effectiveness of HILT.

\section{Declaration of conflicting interests}

The authors declared no conflicts of interest with respect to the authorship and/or publication of this article.

\section{Funding}

The authors received no financial support for the research and/or authorship of this article.

\section{REFERENCES}

1. Shiri R, Viikari-Juntura E, Varonen H, Heliövaara M. Prevalence and determinants of lateral and medial epicondylitis: a population study. Am J Epidemiol 2006;164:1065-74.

2. Smidt N, Lewis M, VAN DER Windt DA, Hay EM, Bouter LM, Croft P. Lateral epicondylitis in general practice: course and prognostic indicators of outcome. J Rheumatol 2006;33:2053-9.

3. Kraushaar BS, Nirschl RP. Tendinosis of the elbow (tennis elbow). Clinical features and findings of histological, immunohistochemical, and electron microscopy studies. J Bone Joint Surg Am 1999;81:259-78. 
4. Wuori JL, Overend TJ, Kramer JF, MacDermid J. Strength and pain measures associated with lateral epicondylitis bracing. Arch Phys Med Rehabil 1998;79:832-7.

5. Bisset L, Paungmali A, Vicenzino B, Beller E. A systematic review and meta-analysis of clinical trials on physical interventions for lateral epicondylalgia. $\mathrm{Br}$ J Sports Med 2005;39:411-22.

6. Struijs PA, Smidt N, Arola H, van Dijk CN, Buchbinder $\mathrm{R}$, Assendelft WJ. Orthotic devices for tennis elbow: a systematic review. Br J Gen Pract 2001;51:924-9.

7. Brown AW, Weber DC. Physical agent modalities. In: Braddom RL, editor. Physical medicine and rehabilitation. London: W.B. Saunders; 2000. p. 440-58.

8. Dundar U, Turkmen U, Toktas H, Ulasli AM, Solak O. Effectiveness of high-intensity laser therapy and splinting in lateral epicondylitis; a prospective, randomized, controlled study. Lasers Med Sci 2015;30:1097-107.

9. Hudak PL, Amadio PC, Bombardier C. Development of an upper extremity outcome measure: the DASH (disabilities of the arm, shoulder and hand) [corrected]. The Upper Extremity Collaborative Group (UECG). Am J Ind Med 1996;29:602-8.

10. Bohannon RW, Schaubert KL. Test-retest reliability of grip-strength measures obtained over a 12-week interval from community-dwelling elders. J Hand Ther 2005; 18:426-7.

11. Ware JE Jr. SF-36 health survey update. Spine (Phila Pa 1976) 2000;25:3130-9.

12. Bjordal JM, Lopes-Martins RA, Joensen J, Couppe C, Ljunggren AE, Stergioulas A, et al. A systematic review with procedural assessments and meta-analysis of low level laser therapy in lateral elbow tendinopathy (tennis elbow). BMC Musculoskelet Disord 2008;9:75.

13. Tumilty S, Munn J, McDonough S, Hurley DA, Basford JR, Baxter GD. Low level laser treatment of tendinopathy: a systematic review with meta-analysis. Photomed Laser Surg 2010;28:3-16.
14. Fiore P, Panza F, Cassatella G, Russo A, Frisardi $\mathrm{V}$, Solfrizzi V, et al. Short-term effects of highintensity laser therapy versus ultrasound therapy in the treatment of low back pain: a randomized controlled trial. Eur J Phys Rehabil Med 2011;47:367-73.

15. Alayat MS, Atya AM, Ali MM, Shosha TM. Longterm effect of high-intensity laser therapy in the treatment of patients with chronic low back pain: a randomized blinded placebo-controlled trial. Lasers Med Sci 2014;29:1065-73.

16. Kheshie AR, Alayat MS, Ali MM. High-intensity versus low-level laser therapy in the treatment of patients with knee osteoarthritis: a randomized controlled trial. Lasers Med Sci 2014;29:1371-6.

17. Alayat MS, Elsodany AM, El Fiky AA. Efficacy of high and low level laser therapy in the treatment of Bell's palsy: a randomized double blind placebo-controlled trial. Lasers Med Sci 2014;29:335-42.

18. Santamato A, Solfrizzi V, Panza F, Tondi G, Frisardi $\mathrm{V}$, Leggin BG, et al. Short-term effects of highintensity laser therapy versus ultrasound therapy in the treatment of people with subacromial impingement syndrome: a randomized clinical trial. Phys Ther 2009;89:643-52

19. Kujawa J, Zavodnik L, Zavodnik I, Buko V, Lapshyna A, Bryszewska M. Effect of low-intensity (3.75-25 J/ $\mathrm{cm} 2)$ near-infrared $(810 \mathrm{~nm})$ laser radiation on red blood cell ATPase activities and membrane structure. J Clin Laser Med Surg 2004;22:111-7.

20. Nicolau RA, Martinez MS, Rigau J, Tomàs J. Neurotransmitter release changes induced by low power $830 \mathrm{~nm}$ diode laser irradiation on the neuromuscular junctions of the mouse. Lasers Surg Med 2004;35:236-41.

21. Jafarian FS, Demneh ES, Tyson SF. The immediate effect of orthotic management on grip strength of patients with lateral epicondylosis. J Orthop Sports Phys Ther 2009;39:484-9. 